\title{
Comment
}

\section{Cerebrovascular Diseases}

Cerebrovasc Dis 2013;36:290-291

DOI: $\underline{10.1159 / 000355142}$

\section{Screening for Diabetes after Stroke and Transient Ischemic Attack}

Walter N. Kernan

Department of Internal Medicine, Yale School of Medicine, New Haven, Conn., USA

Until recently, there were two options for type 2 diabetes screening: fasting plasma glucose (FPG) and the oral glucose tolerance test (OGTT) [1]. Elevated FPG represents primarily an increased endogenous production of glucose by the liver. Elevated 2-hour glucose by the OGTT primarily reflects impaired peripheral glucose disposal in muscle. Excessive production and impaired peripheral disposal are each cardinal features of type 2 diabetes.

In 2010, the American Diabetes Association (ADA) adopted hemoglobin $\mathrm{A}_{1 \mathrm{c}}\left(\mathrm{HbA}_{1 \mathrm{c}}\right)$ as a third screening option [1]. The red blood cell membrane is highly permeable to glucose, which reacts with $\beta$-hemoglobin to form a stable glycation product (i.e. $\mathrm{HbA}_{1 \mathrm{c}}$ ) [2]. $\mathrm{HbA}_{1 \mathrm{c}}$ reflects both hepatic and peripheral glucose metabolism and, therefore, may be a more synthetic measure of glucose metabolism than either FPG or the OGTT alone. Importantly, $\mathrm{Hb}_{1 \mathrm{c}}$ reflects the average glucose concentration over several weeks prior to testing [3]. Distinct advantages of $\mathrm{HbA}_{1 \mathrm{c}}$ over other measures of glycemia are: no requirement for fasting; no perturbation by acute illness or bed rest [4], and less day-to-day variation than with plasma measures of glucose [5]. It is important to note, however, that $\mathrm{HbA}_{1 \mathrm{c}}$ can be affected by conditions that shorten or lengthen red cell life, anemia, uremia and hemoglobin variants [3].

In this issue of Cerebrovascular Diseases, Fonville et al. [6] compare all three screening methods among 700 nondiabetic patients with stroke or transient ischemic attack (TIA) from a prospective registry in The Netherlands. Patients were studied an average of 4 days after their event. Prediabetes and diabetes were classified according to the current ADA guidelines, except that repeat testing was not required [1]. The results from this well-performed study are important. First, they confirm earlier work showing that the prevalence of new prediabetes and diabetes is high among patients with cerebrovascular disease and no prior diagnosis of diabetes [7]. In Fonville et al.'s study [6], 52\% of the patients had newly recognized prediabetes and $27 \%$ had newly recognized diabetes, as defined by a positive finding on any one of the three screening tests.

Second, the results confirm that the OGTT classifies more patients as prediabetic and diabetic than FPG [8-10]. On a more fundamental level, the discordant results demonstrate the greater importance of impaired peripheral glucose disposal (detected by the OGTT) relative to overproduction (detected by FPG) in patients with cerebrovascular disease.

\section{KARGER}

E-Mail karger@karger.com

www.karger.com/ced
Third, the study provides new information on $\mathrm{HbA}_{1 \mathrm{c}}$ screening in patients with stroke and TIA: $\mathrm{HbA}_{1 c}$ identified much fewer patients with diabetes than a single OGTT. This finding is consistent with research on nonstroke populations showing that $\mathrm{HbA}_{1 \mathrm{c}}$ has a sensitivity for diagnosis of diabetes of only $44 \%$ when the OGTT is used as the gold standard [10]. The importance of this reduced sensitivity was downplayed by a recent expert panel that emphasized the strong evidence that an $\mathrm{HbA}_{1 \mathrm{c}}$ threshold of $\geq 6.5 \%$ reliably discriminated between patients at risk for microvascular complications and patients not at risk. [3] $\mathrm{HbA}_{1 \mathrm{c}}$ identifies more patients with prediabetes than either FBG or the OGTT.

So which test is best to screen for prediabetes and diabetes in patients with acute stroke or TIA? In the hospital, $\mathrm{HbA}_{1 \mathrm{c}}$ may be preferred because of the advantages cited above [3]. In newly identified diabetics, furthermore, $\mathrm{HbA}_{1 \mathrm{c}}$ indicates whether they reached the treatment goal $(<7 \%)[1]$. FPG is probably not adequate alone, because it will fail to identify many patients with significantly impaired peripheral glucose disposal. The OGTT will find these persons, but is cumbersome to perform. A factor in favor of the OGTT is that impaired peripheral disposal is probably more closely associated with development of cardiovascular disease compared with impaired fasting glucose [9]. Because each of the three tests provides distinct and complementary information, none should be dismissed and none can be labeled the gold standard [3]. Whichever test is used, the classification of diabetes status requires repeat testing $[1,3,4]$.

The premise of the debate on screening is that it may result in improved clinical outcome after stroke and TIA. The logic of this premise is compelling, but the data to support it are scant. Prediabetes and, more importantly, diabetes are major risk factors for first and recurrent stroke [11-13]. It has not yet been shown, however, that treatment of screen-detected prediabetes or diabetes prevents stroke [14]. What is known is that dietary modification and drugs can prevent progression from prediabetes to diabetes [15] and multifactorial management of diabetes identified by screening is associated with a small, nonsignificant reduction in the incidence of cardiovascular events and death [14]. Patients with stroke and TIA, however, are already targeted for intensive risk factor management, so the added benefit of diabetes screening for prevention of vascular events may be diminished in this population. The benefits of treating established diabetes are better documented. Multifactorial risk factor treatment for established diabetes prevents cardiovascular disease [16]. Tight control of glucose prevents microvascular disease and may prevent macrovascular events in the long run in type 1 and newly diagnosed (not screendetected) type 2 diabetes $[17,18]$.

In summary, on the basis of preliminary evidence that treatment of prediabetes and diabetes may improve health after stroke, screening is reasonable and consistent with current ADA recommendations [1]. No one screening test is fully adequate, but $\mathrm{HbA}_{1 \mathrm{c}}$ screening is probably the best single test. For the future there is important work to be done in developing interventions to improve
Walter N. Kernan, MD

Suite 515

2 Church Street South

New Haven, CT 06519 (USA)

E-Mail walter.kernan@yale.edu 
clinical outcome for patients who screen positive for prediabetes or diabetes. Interventions that address the pathophysiology of diabetes (e.g. weight loss, exercise and nutrition) are obvious candidates. We have only begun to explore the therapeutic implications of data relating prediabetes and diabetes to risk for stroke.

\section{References}

1 American Diabetes Association: Standards of medical care in diabetes: 2013. Diabetes Care 2013;36:S11-S65.

2 Gallagher EJ, le Roith D, Bloomgarden Z: Review of hemoglobin $A_{1 c}$ in the management of diabetes. J Diabetes 2009;1:9-17.

-3 International Expert Committee: The International Expert Committee report on the role of the A1C assay in the diagnosis of diabetes. Diabetes Care 2009;32:1327-1334.

4 Matz K, Keresztes K, Tatschl C, et al: Disorders of glucose metabolism in acute stroke patients. Diabetes Care 2006;29:792-797.

5 Misra A, Garg S: $\mathrm{HbA}_{1 \mathrm{c}}$ and blood glucose for the diagnosis of diabetes. Lancet 2011;378:104-106.

-6 Fonville S, Zandbergen AAM, Vermeer SE, Dippel DWJ, Koudstaal PJ, den Hertog HM: Prevalence of prediabetes and newly diagnosed diabetes in patients with a transient ischemic attack or stroke. Cerebrovasc Dis 2013;36:284-290.

7 Kernan WN, Viscoli CM, Inzucchi SE, et al: Prevalence of abnormal glucose tolerance following a transient ischemic attack or ischemic stroke. Arch Intern Med 2005; 165:227-233.

$>8$ Jia Q, Zheng H, Zhao X, et al: Abnormal glucose regulation in patients with acute stroke across China: prevalence and baseline characteristics. Stroke 2012;43:650-657.

$\checkmark 9$ DECODE Study Group on behalf of the European Diabetes Epidemiology Group: Glucose tolerance and cardiovascular mortality: comparison of fasting and 2-hour diagnostic criteria. Arch Intern Med 2001;161:397405 .
10 Kramer CK, Araneta MRG, Barrett-Connor E: A1C and diabetes diagnosis: the Rancho Bernardo Study. Diabetes Care 2010;33:101-103.

$\checkmark 11$ Emerging Risk Factors Collaboration: Diabetes mellitus, fasting blood glucose concentration, and risk of vascular disease: a collaborative metaanalysis of 102 prospective studies. Lancet 2010;375:2215-2222.

12 Kaplan RC, Tirschwell DL, Longstreth WT, et al: Vascular events, mortality, and preventive therapy following ischemic stroke in the elderly. Neurology 2005;65:835-842.

13 Selvin E, Steffes MW, Zhu H, et al: Glycated hemoglobin, diabetes, and cardiovascular risk in non-diabetic adults. N Engl J Med 2010;362:800811.

14 Griffin SJ, Borch-Johnsen K, Davies MJ, et al: Effect of early intensive multifactorial therapy on 5-year cardiovascular outcomes in individuals with type 2 diabetes detected by screening (ADDITION-Europe): a cluster-randomized trial. Lancet 2011;378:156-167.

15 Diabetes Prevention Program Research Group: Reduction in the incidence of type 2 diabetes with lifestyle intervention or metformin. $\mathrm{N}$ Engl J Med 2002;346:393-403.

16 Gaede P, Vedel P, Larsen N, Jensen GVH, Parving HH, Pedersen O: Multifactorial intervention and cardiovascular disease in patients with type 2 diabetes. N Engl J Med 2003;348:383-393.

17 Holman RR, Paul SK, Bethel A, Matthews DR, Neil AW: 10-year followup of intensive glucose control in type 2 diabetes. N Engl J Med 2008;359: 1577-1589.

18 Diabetes Control and Complications Trial/Epidemiology of Diabetes Interventions and Complications (DCCT/EDIC) Study Research Group: Intensive diabetes treatment and cardiovascular disease in patients with type 1 diabetes. N Engl J Med 2005;353:2643-2653. 